Bull. Mater. Sci., Vol. 16, No. 6, December 1993, pp. 465-476. (C) Printed in India.

\title{
Processing and properties of sintered tool steels and cemented carbides
}

\author{
G S UPADHYAYA
}

Department of Materials and Metallurgical Engineering, Indian Institute of Technology, Kanpur 208016, India

\begin{abstract}
This paper reviews our studies in the area of sintered high speed steels and cemented carbides carried out at the Powder Metallurgy Laboratory of IIT Kanpur under the direction of the author.
\end{abstract}

Keywords. Sintering; powder metallurgy; high speed steels; cemented carbides; tool life.

\section{Introduction}

It is well known that powder metallurgy provides a means of making new alloys and composites of tool materials, which cannot be made by conventional melting, casting and hot working methods.

Powder metallurgy (P/M) processing of high speed steels (HSS) has gained considerable significance over conventional ingot metallurgy (I/M) processing, as the former is more amenable to wide composition variation and has the distinctive advantages of the absence of carbide segregation and minimal carbide and matrix coarsening. The other advantages of $\mathbf{P} / \mathbf{M}$ processed high-speed steels over their conventionally produced counterparts are (Kieffer et al 1974; Harvey 1978; Kar and Upadhyaya 1990): superior grindability in the hardened condition; improved toughness of tools in service; isotropic mechanical properties; faster response to hardening treatment; more uniform size change as a result of hardening heat-treatment; greater cross-sectional uniformity of hardness; near net shape processing requiring minimal finishing operations for making finished tools; and greater yield from the melt.

Among various commercial methods of manufacture of P/M HSS, which differ in terms of powder production and consolidation techniques, liquid phase sintering is gaining importance, as it gives near net shape full density parts. Such a sintering pertains to super solidus category where solid and liquid phases have similar composition (Cambel and Lund 1972).

The continued increase in the consumption of WC-based cemented carbides and the threat from depleting resources of tungsten and cobalt led to a great deal of research for developing alternate cemented carbides compatible with $\mathrm{WC}-\mathrm{Co}$ based materials. The most developed approaches seem to be dilution of WC by other refractory compounds and partial replacement of cobalt by nickel, iron or their alloys. The partial or full substitution of traditional cobalt binder by nickel, iron or their alloys has been fairly well successful (Moskowitz et al 1970; Precht et al 1983; Viswanadham and Lindquist 1987) but not much attempt has been made for the partial replacement of WC by other refractory compounds concurrent to such binder modification.

A change in the chemistry of cemented carbide brings forth a change in the interfacial energy between solid and melt which would affect the wettability and thus 
the first stage of liquid phase sintering. i.e. rearrangement. This in its own turn would affect the solubility behaviour of different constituents of hard phase into the binder and hence the microstructural evolution. The influence of refractory compound additives ( $\mathrm{TiC}$ and $\mathrm{TiN}$ ) on the microstructure and properties of the base $\mathrm{WC}-\mathrm{Co}$ cemented carbide and the necessity of a concurrent change in the binder chemistry to maintain the end properties have been discussed in detail elsewhere (Bhaumik et al 1992a, b, c).

The present paper describes the results of investigation carried out in the author's laboratory on sintered high speed steels (T15 and T42 grades) and cemented carbides based on WC-10Co composition.

\section{Experimental procedure}

The experimental procedure followed for investigation of the high speed steel and cemented carbides is reported elsewhere (Bhaumik et al 1992c; Kar et al 1993). The properties measured were sintered density, Vickers hardness, transverse rupture strength (TRS), elevated temperature compressive strength and cutting tool life. In addition microstructural studies, both qualitative and quantitative, were carried out. The composition and characteristics of the high speed steel powders used are given

Table 1. Composition and powder characteristics of T15 and T42 high speed steels.

\begin{tabular}{|c|c|c|}
\hline \multirow{3}{*}{ Characteristics } & \multicolumn{2}{|c|}{ High speed steel } \\
\hline & \multicolumn{2}{|c|}{$\begin{array}{c}\text { Source: British Indian Steel Co. } \\
\text { Ahmedabad }\end{array}$} \\
\hline & T15 & T42 \\
\hline \multicolumn{3}{|c|}{ Chemical composition, mass $\%$} \\
\hline Carbon & 1.60 & 1.3 \\
\hline Chromiur & $4 \cdot 12$ & 3.96 \\
\hline Cobalt & 4.95 & 10.60 \\
\hline Manganese & 0.40 & 0.22 \\
\hline Molybdenum & 1.31 & 4.01 \\
\hline Tungsten & $12 \cdot 30$ & 9.70 \\
\hline Vanadium & $5 \cdot 26$ & $2 \cdot 39$ \\
\hline Sulphur & $0.04 \max$ & 0.044 \\
\hline Phosphorus & 0.04 & $0-044$ \\
\hline Oxygen & $1400 \mathrm{ppm}$ & 700 ppm \\
\hline \multicolumn{3}{|c|}{$\begin{array}{l}\text { Sieve analysis } \\
(\% \text { cumulative mass fraction) }\end{array}$} \\
\hline Mesh +100 & 0.09 & 4.49 \\
\hline Mesh +150 & $9 \cdot 15$ & $15 \cdot 32$ \\
\hline Mesh +200 & 27.95 & 38.85 \\
\hline Mesh +350 & $68 \cdot 15$ & 81.62 \\
\hline Mesh -350 & 31.85 & $18 \cdot 30$ \\
\hline Apparent density, g/cc & $2 \cdot 49$ & $2 \cdot 42$ \\
\hline Flow rate, $\mathrm{s} / 50 \mathrm{~g}$ & 41 & $43 \cdot 3$ \\
\hline $\begin{array}{l}\text { Compressibility, } \mathrm{g} / \mathrm{cc} \\
(\% \text { at } 30 \mathrm{TSi})\end{array}$ & 5.54 & $5 \cdot 58$ \\
\hline
\end{tabular}


in table 1 . The starting composition of the cemented carbide (WC-10Co) corresponds to approximately 17 vol.\% binder phase. All the subsequent compositions developed later were tailored so that the volume fraction of the hard and binder phases remained constant as that of the initial $\mathrm{WC}-10 \mathrm{Co}$ cemented carbide. The respective mass percent additives in modified cemented carbide compositions are given in table 2.

\section{Results}

\subsection{Sintered high speed steels}

The densification behaviour of vacuum-sintered T15 and T42 HSS is shown in figures la and $2 \mathrm{a}$ respectively. Sintered density of vacuum sintered T15 HSS increased with increase in sintering temperature from about $87 \%$ of theoretical density at $1250^{\circ} \mathrm{C}$ to $98 \%$ at $1270^{\circ} \mathrm{C}$. Similarly, the sintered density of T42 HSS increased from $85 \%$ at $1220^{\circ} \mathrm{C}$ to $98.5 \%$ at $1230^{\circ} \mathrm{C}$. The densification behaviour of hydrogen sintered T15 and T42 HSS in shown in figures $3 \mathrm{a}$ and $3 \mathrm{~b}$. In the case of hydrogen sintering like vacuum sintering, sintered density increased with increase in temperature.

The sintered hardness variation of vacuum-sintered T15 and T42 HSS with respect to sintering temperature is shown in figures $1 \mathrm{~b}$ and $2 \mathrm{~b}$ respectively. The plot follows a trend similar to that observed for densification with respect to sintering temperature. The as-sintered as well as heat-treated hardness of hydrogen-sintered T15 and T42 HSS is shown in figure $3 \mathrm{c}$.
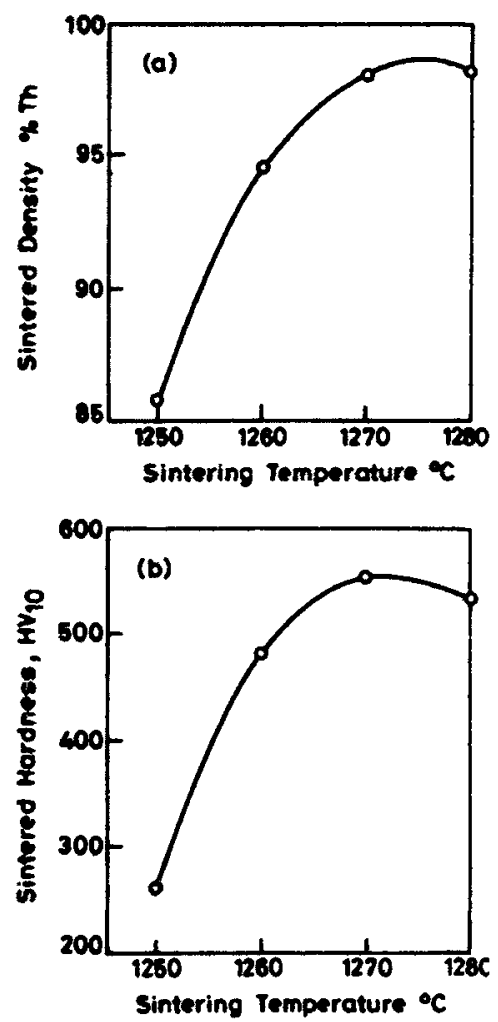

Figure 1. Effect of sintering temperature on (a) sintered density and (b) Vickers hardness of T15 HSS after vacuum sintering. 


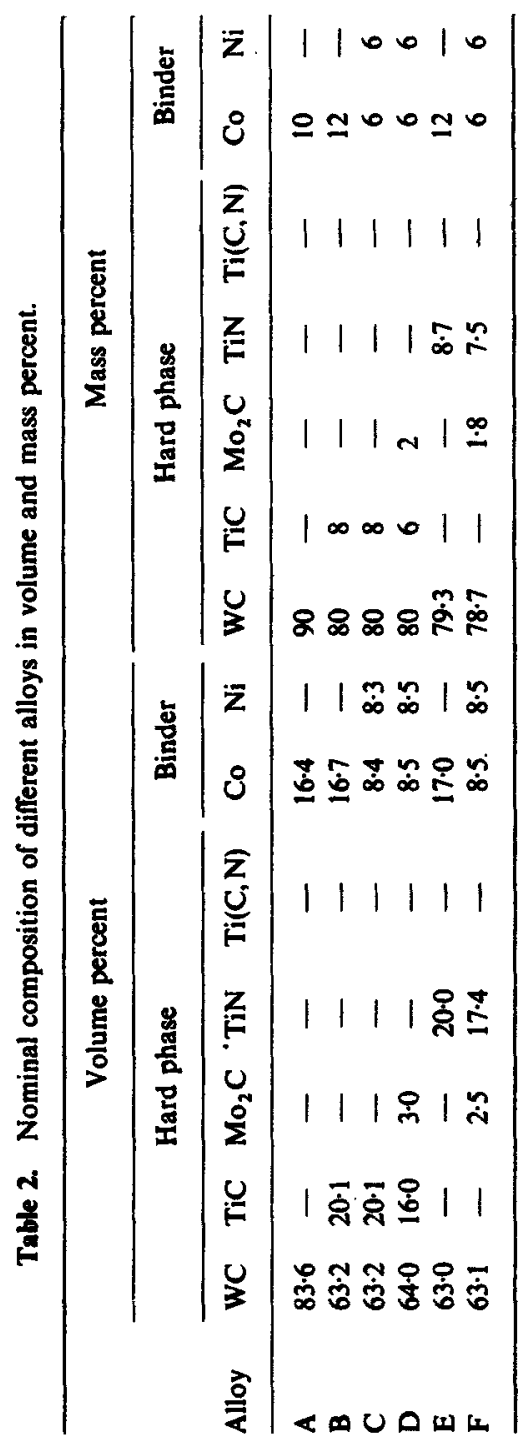



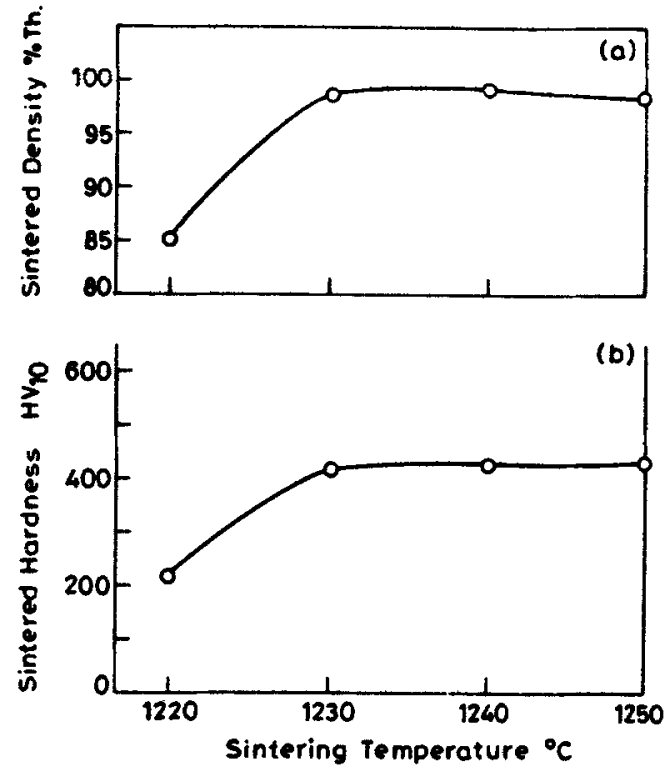

Figure 2. Effect of sintering temperature on (a) sintered density and (b) Vickers hardness of T42 HSS after vacuum sintering.
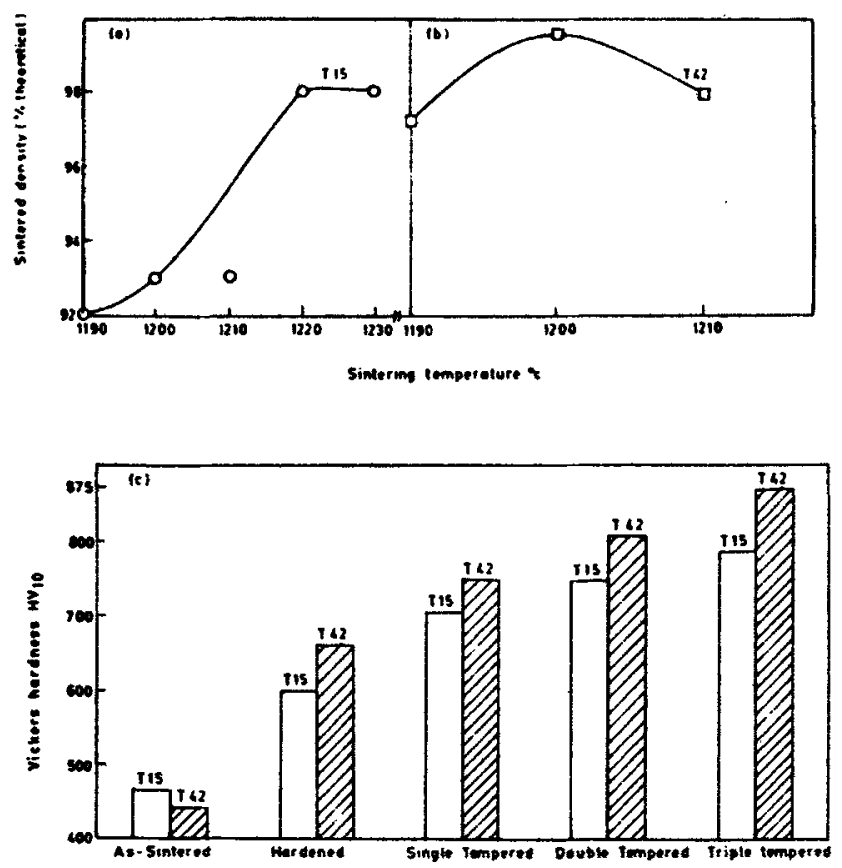

Figure 3. Sintered density as a function sintering temperature in hydrogen for T15 (a) and T42 (b). Also Vickers hardness of T15 and T42 HSS as a function of heat treatment (c). 


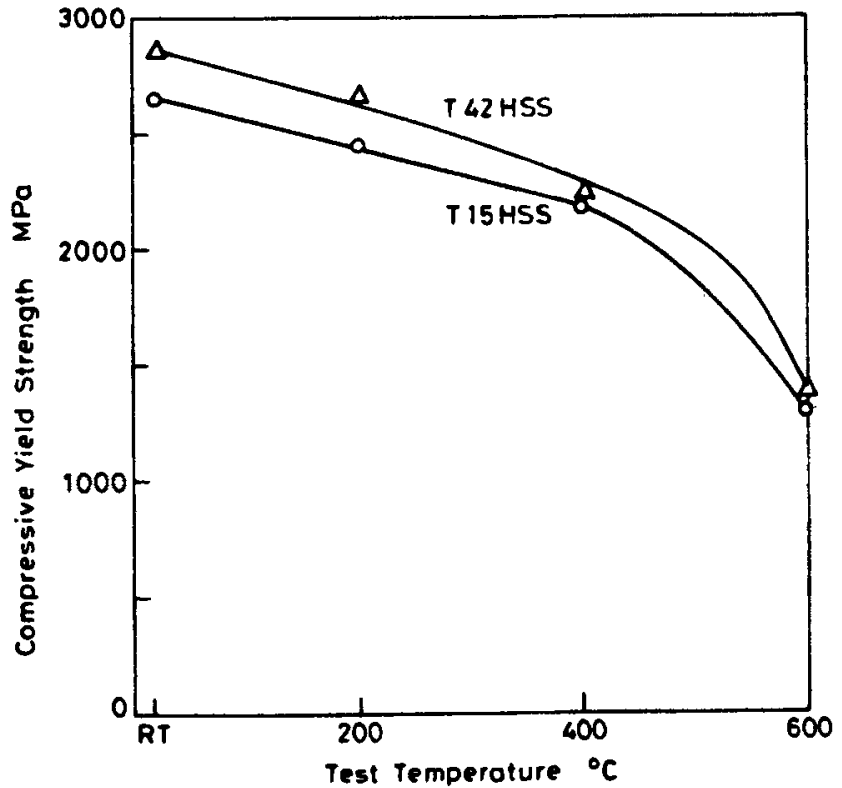

Figure 4. Effect of temperature as the $0.2 \%$ offset yield strength (compression) of fully heat-treated T15 and T42 HSS.

The as-sintered TRS of T15 and T42 HSS was $1500 \mathrm{MPa}$ and $1899 \mathrm{MPa}$ respectively and the TRS in triple tempered condition for T15 and T42 (vacuum-sintered at the respective optimum sintering temperature) was $1950 \mathrm{MPa}$ and $1300 \mathrm{MPa}$ respectively. The sintered TRS of T15 was lower than that of T42 whereas the reverse was true in the case of triple tempered TRS.

The variation of elevated temperature compressive yield strength of T15 and T42 HSS is shown in figure 4. It is evident that at any testing temperature $0.2 \%$ offset compressive yield strength for T42 HSS is higher than the corresponding T15 HSS. In both cases, there is a rapid fall in yield strength beyond $500^{\circ} \mathrm{C}$.

It was found that at a cutting speed of $70 \mathrm{~m} / \mathrm{min}$ the heat-treated T42 HSS had a longer tool life (30 min) as compared to that for T15 HSS (21 min) under identical test conditions.

\subsection{Cemented carbides}

The full density of alloy $\mathrm{A}$ was achieved after sintering at $1425^{\circ} \mathrm{C}$. The change in sintering atmosphere from hydrogen to vacuum resulted in higher sintered density (table 3). This shows that the full density of WC-8TiC-12Co (alloy B), WC-8TiC$6 \mathrm{Co}-6 \mathrm{Ni}$ (alloy $\mathrm{C}$ ) and $\mathrm{WC}-6 \mathrm{TiC}-2 \mathrm{Mo}_{2} \mathrm{C}-6 \mathrm{Co}-6 \mathrm{Ni}$ (alloy $\mathrm{D}$ ) cemented carbides was achieved only after $1475^{\circ} \mathrm{C}$ sintering. The modification in binder phase (alloys $C$ and $D$ ) resulted in better densification behaviour. Alloys $C$ and $D$ achieved almost full density at a sintering temperature of $1450^{\circ} \mathrm{C}$. The effect of sintering atmosphere on the final sintered density of alloys $\mathrm{B}, \mathrm{C}$ and $\mathrm{D}$ was the same as that mentioned earlier in the case of alloy $A$.

Introduction of TiN into WC-10Co cemented carbide (alloy A) resulted in highsintered porosity. The maximum attainable sintered density in WC-8.7TiN-12 Co 
Table 3. Densification of different cemented carbides after liquid phase sintering and hot isostatic pressing (HIPing).

\begin{tabular}{|c|c|c|c|c|c|c|c|}
\hline \multirow[b]{4}{*}{ Alloy } & \multirow{4}{*}{$\begin{array}{l}\text { Sintering } \\
\text { atmosphere }\end{array}$} & \multicolumn{6}{|c|}{ Densification (\% theoretical density) } \\
\hline & & \multirow{2}{*}{\multicolumn{4}{|c|}{ After LPS $^{*}$ at ${ }^{\circ} \mathrm{C}$}} & \multicolumn{2}{|c|}{ LPS $^{*}$ at $1475^{\circ} \mathrm{C}$} \\
\hline & & & & & & and subsequently & HIP'ped at ${ }^{\circ} \mathrm{C}$ \\
\hline & & 1425 & 1450 & 1475 & 1500 & 1400 & 1450 \\
\hline \multirow{2}{*}{ A } & $\mathbf{H}_{2}$ & 100 & - & - & - & - & - \\
\hline & vac. & 100 & - & - & - & - & - \\
\hline \multirow{2}{*}{ B } & $\mathbf{H}_{2}$ & - & 98.70 & 100 & 100 & - & - \\
\hline & vac. & - & - & 100 & - & - & - \\
\hline \multirow{2}{*}{ C } & $\mathbf{H}_{2}$ & - & 99.60 & 100 & - & - & - \\
\hline & vac. & - & - & 100 & - & - & - \\
\hline \multirow{2}{*}{ D } & $\mathbf{H}_{2}$ & - & $99 \cdot 80$ & 100 & - & - & - \\
\hline & vac. & - & - & 100 & - & - & - \\
\hline \multirow{2}{*}{$\mathbf{E}$} & $\mathbf{H}_{2}$ & - & $93 \cdot 72$ & 95.65 & 95.71 & - & - \\
\hline & $\mathbf{H}_{2}+\mathbf{N}_{2}$ & - & 96.05 & 96.36 & 96.61 & 99.59 & 99.85 \\
\hline $\mathbf{F}$ & $\mathrm{H}_{2}+\mathrm{N}_{2}$ & - & 96.04 & 96.75 & 96.97 & $99 \cdot 70$ & 99.90 \\
\hline
\end{tabular}

* LPS, liquid phase-sintered.

(alloy E) was achieved at $1475^{\circ} \mathrm{C}$ (table 3). A greater improvement in sintered density was observed when the sintering atmosphere was changed to $\mathrm{H}_{2}-\mathrm{N}_{2}$ mixture $(50: 50)$ from straight $\mathrm{H}_{2}$. Even then the maximum attainable density was about $96 \%$ of the theoretical density. Table 3 reveals that the addition of $\mathrm{Ni}$ and $\mathrm{Mo}_{2} \mathrm{C}$ (alloy $\mathrm{F}$ ) improved the densification behaviour significantly. The maximum attainable density was achieved at $1475^{\circ} \mathrm{C}$ and no further improvement was observed at the higher sintering temperature.

Nearly full density with residual porosity in the range 0.10 to $0.15 \%$ was achieved when hot isostatic pressing (HIPing) of the liquid phase sintered alloys was done at $1450^{\circ} \mathrm{C}$. Large pores in the as-sintered compacts were mostly eliminated by HIP treatment. The pore size was further reduced when the HIPing temperature was increased to $1450^{\circ} \mathrm{C}$ from $1400^{\circ} \mathrm{C}$. HIPing at $1450^{\circ} \mathrm{C}$ resulted in finer pores and much uniform distribution than those at $1400^{\circ} \mathrm{C}$.

Mechanical properties of different cemented carbides used in our study are presented in table 4 . The introduction of $\mathrm{TiC}$ into $\mathrm{WC}-10 \mathrm{Co}$-cemented carbide resulted in a drastic fall in TRS and fracture toughness though the hardness level was almost the same. Substitution of 50 vol. \% binder metal cobalt by nickel in WC- $8 \mathrm{TiC}-12 \mathrm{Co}-$ cemented carbide resulted in a marginal decrease in hardness but the TRS increased by about $325 \mathrm{MPa}$. TRS and fracture toughness improved significantly when TiC in WC-8TiC-6Co-Ni cemented carbide was substituted partially by $\mathrm{Mo}_{2} \mathrm{C}$ (alloy D). This particular composition showed that TRS (2250 MPa) was almost equivalent to that of alloy $A$. The hardness value of alloy $D$ was slightly greater than that for WC-10Co-cemented carbide. 
Table 4. Mechanical properties of different cemented carbides after liquid phase sintering and hot isostatic pressing.

\begin{tabular}{|c|c|c|c|c|}
\hline Alloy & Consolidation parameter & $\begin{array}{l}\text { Hardness } \\
\text { (HV30) }\end{array}$ & $\begin{array}{c}\text { TRS } \\
\text { (MPa) }\end{array}$ & $\begin{array}{l}\text { Indentation } \\
\text { fracture } \\
\text { toughness } \\
\left(\mathrm{MPa} \mathrm{m}^{1 / 2} \text { ) }\right.\end{array}$ \\
\hline A & $\begin{array}{r}\mathrm{LPS}^{*} \text { at } 1425^{\circ} \mathrm{C} \text { in } \mathrm{H}_{2} \\
\text { vac. }\end{array}$ & $\begin{array}{l}1370 \\
1280\end{array}$ & $\begin{array}{l}2320 \\
2380\end{array}$ & $\begin{array}{l}11 \cdot 20 \\
11 \cdot 87\end{array}$ \\
\hline B & $\begin{array}{r}\text { LPS at } 1475^{\circ} \mathrm{C} \text { in } \mathrm{H}_{2} \\
\text { vac. }\end{array}$ & $\begin{array}{l}1395 \\
1381\end{array}$ & $\begin{array}{l}1400 \\
1620\end{array}$ & $\begin{array}{l}10 \cdot 20 \\
10 \cdot 40\end{array}$ \\
\hline $\mathrm{C}$ & $\begin{array}{r}\text { LPS at } 1475^{\circ} \mathrm{C} \text { in } \mathrm{H}_{2} \\
\text { vac. }\end{array}$ & $\begin{array}{l}1380 \\
1263\end{array}$ & $\begin{array}{l}1740 \\
1820\end{array}$ & $\begin{array}{l}9 \cdot 70 \\
9 \cdot 84\end{array}$ \\
\hline D & $\begin{array}{r}\text { LPS at } 1475^{\circ} \mathrm{C} \text { in } \mathrm{H}_{2} \\
\text { vac. }\end{array}$ & $\begin{array}{l}1385 \\
1262\end{array}$ & $\begin{array}{l}2260 \\
2320\end{array}$ & $\begin{array}{l}10 \cdot 45 \\
10.52\end{array}$ \\
\hline $\mathbf{E}$ & $\begin{array}{l}\text { LPS at } 1475^{\circ} \mathrm{C} \text { in } \mathrm{H}_{2} \\
\mathrm{H}_{2}+\mathrm{N}_{2} \\
\text { LPS at } 1475^{\circ} \mathrm{C} \text { in } \mathrm{H}_{2}+\mathrm{N}_{2} \\
\text { followed by } \mathrm{HIPing} \text { at } \\
\qquad \begin{array}{r}1400^{\circ} \mathrm{C} \\
1450^{\circ} \mathrm{C}\end{array}\end{array}$ & $\begin{array}{l}1321 \\
1112\end{array}$ & $\begin{array}{l}1190 \\
1795\end{array}$ & $\begin{array}{r}9 \cdot 48 \\
10-78\end{array}$ \\
\hline $\mathbf{F}$ & $\begin{array}{l}\text { LPS at } 1475^{\circ} \mathrm{C} \text { in } \mathrm{H}_{2}+\mathrm{N}_{2} \\
\text { LPS at } 1475^{\circ} \mathrm{C} \text { in } \mathrm{H}_{2}+\mathrm{N}_{2} \\
\text { followed by } \mathrm{HIPing} \text { at } \\
\qquad \begin{array}{r}1400^{\circ} \mathrm{C} \\
1450^{\circ} \mathrm{C}\end{array}\end{array}$ & $\begin{array}{l}1265 \\
1285\end{array}$ & $\begin{array}{l}1837 \\
2155\end{array}$ & $\begin{array}{r}9 \cdot 34 \\
10 \cdot 63\end{array}$ \\
\hline
\end{tabular}

* LPS, liquid phase-sintered.

From table 4 it is clear that HIPing enhanced the mechanical properties of $E$ and $F$ alloys. The only exception was the indentation fracture toughness value after HIPing at $1400^{\circ} \mathrm{C}$ which showed a decrease. TiN containing cemented carbides (alloys $\mathrm{E}$ and F) have better TRS and indentation fracture toughness than those of TiC containing ones for any particular composition. In the case of TiN addition the best strength properties were obtained with cobalt binder and any modification in the binder phase chemistry led to deterioration in TRS and indentation fracture toughness.

\section{Discussion}

\subsection{High speed steels}

The densification process of high speed steels can be related to sintering temperature and atmosphere. The optimum sintering temperature to achieve full density for T15 HSS was $1270^{\circ} \mathrm{C}$ as compared to $1230^{\circ} \mathrm{C}$ for T42 HSS for vacuum-sintered samples (figures 1 and 2) and for hydrogen-sintered samples it was $1220^{\circ} \mathrm{C}$ and $1200^{\circ} \mathrm{C}$ respectively (figures $3 a$ and $b$ ). T15 even with higher carbon content than that of T42 HSS, required a relatively higher sintering temperature mainly because of its relatively 
high $\mathrm{W}$ and $\mathrm{V}$ content and lower Mo content. It is well known that Mo reduces the solidus temperature of steel more than W (Gill 1944; Hoyle 1980). The effect of vanadium in HSS is to shift the phase boundaries more towards the right i.e. equivalent to a decrease in the carbon content. These results show that the solidus temperature for T15 is higher than that for T42 HSS. Similar conclusion can be drawn from the balance carbon difference ( $\mathrm{Ni}$ and Wang 1990) between the two grades of high speed steels.

As regards sintering atmosphere, hydrogen-sintered HSS requires a lower sintering temperature to achieve nearly full density than vacuum-sintered HSS. It was noticed that in the case of T15 HSS, a temperature difference of $50^{\circ} \mathrm{C}$ lies between vacuum and hydrogen sintering for achieving equivalent density. However, in the case of T42 HSS this difference was only $30^{\circ} \mathrm{C}$. The lower temperature requirement for nearly full densification in the case of hydrogen sintering can be attributed to the fact that it has a good thermal conductivity and during sintering each fresh oxide surface of metal immediately gets reduced by hydrogen (Gill 1944).

Higher sintered hardness of T15 HSS in comparison to that of sintered T42 HSS may be attributed to the higher dissolution of alloying elements during elevated temperature sintering in the matrix of the former thus causing solid solution hardening (figures $1 \mathrm{~b}$ and $2 \mathrm{~b}$ ). The higher hardness values of T42 HSS after tempering as compared to T15 HSS (figure 3c) were due to the high cobalt content in T42 HSS. Cobalt enhances the diffusivity of carbon by which greater precipitation of alloy carbides from the retained austenite occurs in cobalt-rich HSS. As a result, the carbon content of the remaining austenite decreases thereby increasing the $M_{s}$ temperature. It becomes possible for the remaining austenite to get transformed to martensite during cooling after subsequent tempering. Cobalt containing steels, thus have less amount of retained austenite as compared to the non-cobalt-bearing grades. During tempering, cobalt in HSS promotes greater precipitation of W and Mo from martensite as finely dispersed secondary carbides.

The higher triple-tempered hardness of T42 HSS in comparison to that of T15 HSS is once again attributed to the higher cobalt content in the matrix. The combined effect of cobalt in strengthening the matrix and the dispersion strengthening due to the presence of very fine stable carbide precipitates which restrict the dislocation motion results in a relatively higher triple-tempered hardness for T42 HSS. It is also known that cobalt decreases the stability of retained austenite during tempering in addition to the solid solution strengthening of the matrix (Ubrain 1961; Chandhok et al 1962, 1963; Habraken and Coutsourdis 1965; Magnee et al 1974; Geller 1978). It is obvious that the precipitated carbides in a concentrated solid solution-hardened matrix would result in a stronger alloy as compared to similar precipitates in leaner solid solutions. Similarly, carbide precipitates in a fine-grained matrix would impart further strengthening than that in coarse-grained HSS with equivalent amount and type of precipitates.

A relatively lower triple-tempered TRS value of T42 HSS (for either vacuum or hydrogen sintering) as compared to that of T15 HSS may be attributed to the relatively larger cobalt content of T42 HSS (Leckie-Ewing 1950; Geller 1978; Woodhead and Quarrell 1985), which induces very fine dislocation-nucleated precipitates of alloy carbides both in retained austenite and martensite leading to retention of dislocation substructure. 


\subsection{Cemented carbides}

Even though the volume percent of binder phase cobalt was the same in alloys $A$ and $\mathrm{B}$, the full density in alloy $\mathrm{B}$ was achieved at $1475^{\circ} \mathrm{C}$ which was $50^{\circ} \mathrm{C}$ higher than that of alloy $A$ (table 3 ). The increase in sintering temperature with respect to alloy $A$ is believed to be due to poor wettability and solubility of $\mathrm{TiC}$ in liquid cobalt. Cobalt dissolves only 1 mass $\% \mathrm{TiC}$ at $1250^{\circ} \mathrm{C}$ and has a wetting angle of $25^{\circ} \mathrm{C}$ (in vacuum) at $1420^{\circ} \mathrm{C}$ (Exner 1979; Kisley 1985). Because of high dihedral angle, the liquid cobalt penetration into $\mathrm{WC} / \mathrm{TiC}$ or $\mathrm{TiC} / \mathrm{TiC}$ grain boundaries becomes restricted and thereby makes the first stage of liquid phase sintering, i.e. rearrangement of grains less efficient than that in WC-Co system. Secondly, since the solubility of $\mathrm{TiC}$ in cobalt is less, the $\mathrm{TiC}$ grain surface smoothening takes place very slowly, further restricting the rearrangement stage which contributes a maximum to densification in liquid phase sintering. In such a situation a higher liquid phase is required to obtain full density within the practical sintering period. Increase in sintering temperature not only increases the amount of liquid phase but also lowers the solid/liquid interfacial energy which helps in better liquid penetration into the solid grain interfaces and facilitates the solution reprecipitation.

Coming to alloy $\mathrm{C}$, the quasibinary phase diagrams of $\mathrm{Ti}-\mathrm{C}-\mathrm{Co}$ and $\mathrm{Ti}-\mathrm{C}-\mathrm{Ni}$ systems are available, which suggest that minimum liquid phase formation temperature decreases as the binder metal is replaced from cobalt to nickel. But the reverse is true for $\mathrm{W}-\mathrm{C}-\mathrm{Co}$ and $\mathrm{W}-\mathrm{C}-\mathrm{Ni}$ systems (Gabriel et al 1987). On the other hand, nickel dissolves 12 and 5 mass \% of $\mathrm{WC}$ and $\mathrm{TiC}$ respectively into it at a temperature of $1250^{\circ} \mathrm{C}$ and they have contact angles of 0 and $23^{\circ}$ respectively in vacuum at a temperature of $1380^{\circ} \mathrm{C}$ (Exner 1979; Kisley 1985). As regards WC, nickel is inferior to cobalt binder from the solubility point of view, but the reverse is true for TiC in respect of both wettability and solubility. This suggests that cobalt-nickel binder instead of only cobalt could be a reasonably good compromise for the cemented carbides containing both WC and TiC.

As mentioned above, the wettability and solubility of $\mathrm{TiC}$ in nickel are better than those in cobalt. The partial replacement of binder cobalt by nickel, therefore, promoted the solution-reprecipitation of $\mathrm{TiC}$ without causing much problem with WC. This appears to be the main reason for a better densification of alloy $\mathrm{C}$ as compared to alloy $\mathbf{B}$.

It is well known that the presence of molybdenum in cobalt-nickel binder lowers the solid/liquid interfacial energy thus ensuring a better wetting of the hard phase grains viz. WC and TiC (Barranco and Warenchak 1989). With this in view, alloy $\mathrm{C}$ was further modified by including molybdenum into the system in the form of $\mathrm{Mo}_{2} \mathrm{C}$.

It is obvious from the results (table 3) that the full density of alloy $\mathrm{E}$ was not achieved even at a sintering temperature of $1500^{\circ} \mathrm{C}$ presumably due to the poor wettability of TiN with cobalt. Densification behaviour in nitrogen containing cemented carbides is especially influenced by sintering atmosphere. Such cemented carbides cannot be sintered in dynamic vacuum or in hydrogen, because $\mathrm{TiN}$ tends to decompose causing the formation of micro- and macro-porosity (Kisly and Kuzenkova 1972; Ettmayer et al 1991). The present results indicate that such a feature occurred in alloy $\mathrm{E}$ as well. This diminishes the carbon content from WC facilitating $\eta$ phase formation. This phase involves consumption of cobalt which otherwise produces liquid at the sintering temperature. Secondly, depletion of carbon in the 
alloy reduces the fluidity of the liquid melt during sintering. These effects ultimately lead to higher sintered porosity in the hydrogen-sintered cemented carbides of such grades.

The liquid phase sintering results showed that it is virtually impossible to achieve a fully dense product out of TiN containing cemented carbides, irrespective of the variation in sintering atmosphere. This may arise from the fact that pores containing nitrogen arising out of denitrification are difficult to move out during sintering and invariably gives rise to large pores in the sintered compacts (Kisly and Kuzenkova 1972). These pores are the fracture origin and are responsible for low strengths. HIPing of such liquid phase-sintered compacts becomes obvious to eliminate such defects and to achieve increased strength.

HIP treatment after liquid phase sintering was found to be effective for eliminating large pores, though some small pores were still left out. HIPing at $1400^{\circ} \mathrm{C}$ did not eliminate all large pores in the sintered compact, which may be due to the fact that liquid phase sintering resulted in continuous hard phase skeleton formation and during HIPing at $1400^{\circ} \mathrm{C}$, the contributions of power law creep/plastic deformation and amount of liquid phase were not sufficient enough to eliminate the large pores completely. However, such large pores were completely eliminated when HIPing temperature was raised to $1450^{\circ} \mathrm{C}$.

A substantial increase in tool life in modified grades of cemented carbides (figure 5) is attributed to the better TRS and toughness brought about by better densification. The premature failure in alloys $\mathrm{B}$ and $\mathrm{C}$ was mainly because of poor strength resulting in nonuniform microstructure (Bhaumik et al 1992).

\section{Conclusion}

The innovation in the liquid phase sintering provided us a powerful means for developing sintered tool steels and cemented carbides more economically, when the basic concepts of alloy chemistry were involved.

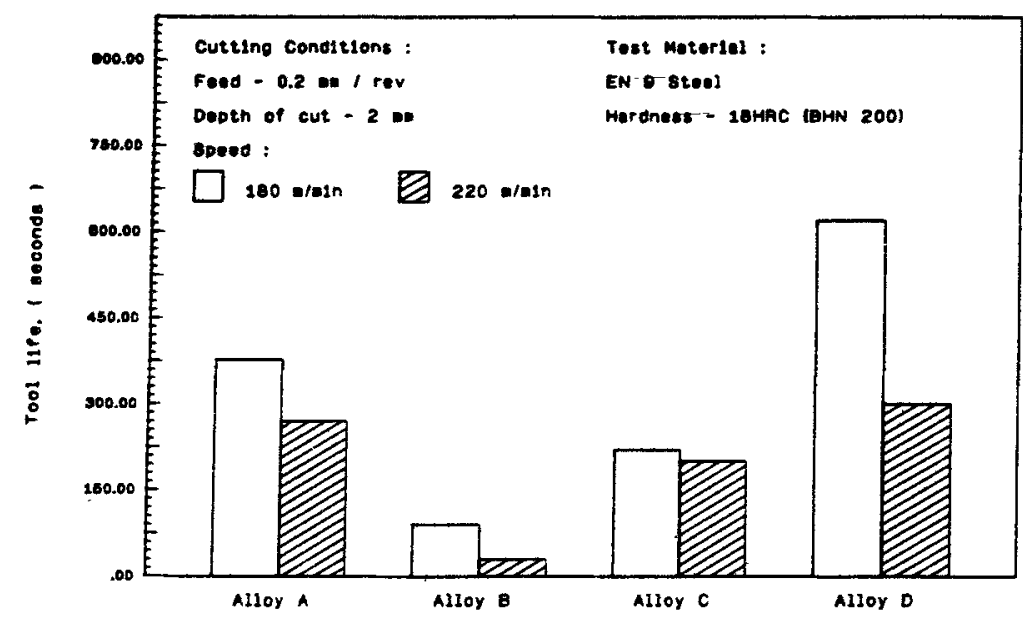

Figure 5. Tool life variation of cemented carbides (A, B, C and D), sintered in hydrogen. 


\section{Acknowledgement}

The author is grateful to all his research students who have toiled in his Powder Metallurgy Laboratory during the past 15 years.

\section{References}

Barranco J M and Warenchak R A 1989 Int. J. Refract. Metals Hard Mater. 8102

Bhaumik S K, Upadhyaya G S and Vaidya M L 1992a Int. J. Refract. Metals Hard Mater. 119

Bhaumik S K, Upadhyaya G S and Vaidya M L 1992b J. Mater. Sci. 271947

Bhaumik S K, Upadhyaya G S and Vaidya M L 1992c Mater. Charact. 28241

Cambel L and Lund I A 1972 Int. J. Powder Metall. 8131

Chandhok V K, Hirth J P and Dulis E J 1962 Trans. AIME 224858

Chandhok V K, Hirth J P and Dulis E J 1963 Trans. ASM 56677

Ettmayer P, Kolaska H and Dreyer K 1991 Powder Metall. Int. 23224

Exner H E 1979 Int. Metals Rev. 24149

Gabriel A, Pastor H, Deo D M, Basu S and Allibert C H 1987 in Sintering 85 (eds) G C Kuczynski, D P Uskokovic, H Palmour III and M M Ristic (New York: Plenum Press) pp 379-393

Geller Yu 1978 Tool steels (Moscow: MIR Publishers) pp 440-455

Gill J B 1944 Tool steels (Metals Park, Ohio: ASM) pp 494-529

Habraken L and Coutsouradis D 1965 Cobalt 1

Hoyle G 1980 High speed steels (London: Butterworths)

Harvey R P 1978 Preformed P/M tool steel for cutting tools (Michigan: Society of Manufacturing Engineers)

Kar P K and Upadhyaya G S 1990 Powder Metall. Int. 2223

Kar P K, Saha B P and Upadhyaya G S 1993 Int. J. Powder Metall. 29139

Kieffer R, Meyer P E H, Jangg G and Weissmann G 1974 in Modern developments in powder metallurgy (eds) H Hausner and W E Smith (Princeton: Metal Powder Industries Federation) 8 pp 1-18

Kisly P S 1985 Kermeti, Naukota Dumka, Kiev (in Russian)

Kisly P S and Kuzenkova M A 1972 Powder Metall. Int. 467

Leckie-Ewing $P 1950$ Iron Age 115

Magnee A, Drapier J M, Dumont J, Coutsouradis D and Habraken L 1974 Cobalt containing high strength steels (Brussels: Centre D'Information Du Cobalt)

Moskowitz D, Ford M J and Humenik M Jr 1970 Int. J. Powder Metall. 655

Ni S and Wang S 1990 Proc. of the first int. high speed steel conf. (eds) G Hackl and B Hribernick (Leoben: Montan Universitat) pp 438-446

Precht W, Viswanadham R K and Venables J D 1983 in Science of hard materials (eds) R K Viswanadham, D J Rowcliffe and J Gurland (New York: Plenum Press) pp 815-827

Ubrain M 1961 Cobalt 1

Viswanadham R K and Lindquist P G 1987 Metall. Trans. A18 2163

Woodhead J H and Quarrell A G 1985 The role of carbides in low alloy and creep resisting steels (London: Climax Molybdenum Co. Ltd.) 